\title{
Harnessing anaerobic digestion for combined cooling, heat, and power on dairy farms: An environmental life cycle and techno-economic assessment of added cooling pathways
}

\author{
J. G. Usack, ${ }^{1,2}$ L. Gerber Van Doren, ${ }^{3,4,5}$ R. Posmanik, ${ }^{3,4,6}$ J. W. Tester, ${ }^{3,4,7}$ and L. T. Angenent ${ }^{1,2,7 *}$ \\ ${ }^{1}$ Center for Applied Geosciences, University of Tübingen, Tübingen 72074, Germany \\ ${ }^{2}$ Department of Biological and Environmental Engineering, Cornell University, Ithaca, NY 14853 \\ ${ }^{3}$ School of Chemical and Biomolecular Engineering, Cornell University, Ithaca, NY 14853 \\ ${ }^{4}$ Cornell Energy Systems Institute, Cornell University, Ithaca, NY 14853 \\ ${ }^{5}$ Curriculum in Environment and Ecology, University of North Carolina at Chapel Hill, Chapel Hill 27514 \\ ${ }^{6}$ Institute of Soil, Water, and Environmental Science, Agricultural Research Organization, Volcani Center, Ramat Yishay 30095, Israel \\ ${ }^{7}$ Atkinson Center for a Sustainable Future, Cornell University, Ithaca, NY 14853
}

\section{ABSTRACT}

Anaerobic digestion coupled with combined heat and power production on dairy farms is environmentally advantageous; however, high capital and operating costs have limited its adoption, especially in the United States, where renewable electricity and heat production are under-incentivized. Biogas is also at a disadvantage because it has to compete with very low natural gas prices. The objective of this study was to evaluate the feasibility of integrating absorption refrigeration technology for combined cooling, heat, and power (CCHP) on the farm to help bridge this economic hurdle. A combined environmental life cycle and techno-economic assessment was used to compare 2 cooling pathways with and without co-digestion. We considered using CCHP to (1) displace electricity-driven refrigeration processes (e.g., milk chilling/refrigeration, biogas inlet cooling) or (2) mitigate heat stress in dairy cattle via conductive cow cooling. All cooling scenarios reduced environmental emissions compared with combined heat and power only, with an appreciable reduction in land use impacts when employing conductive cow cooling. However, none of the cooling scenarios achieved economically viability. When using cooling power to displace electricity-driven refrigeration processes, economic viability was constrained by low electricity prices and a lack of incentives in the United States. When used for conductive cow cooling, economic viability was constrained by (1) low waste heat-to-cooling conversion efficiency; (2) limited conductive cow cooling effectiveness (i.e., heat-stress mitigation); and (3) low

Received August 8, 2018.

Accepted November 29, 2018.

*Corresponding author: l.angenent@uni-tuebingen.de heat stress frequency and limited severity. However, we predict that with minor improvements in conductive cow cooling effectiveness and in hotter climates, CCHP for conductive cow cooling would be economically viable even in current US energy markets.

Key words: anaerobic digestion, conductive cooling, heat stress, dairy cow, net metering

\section{INTRODUCTION}

Anaerobic digestion (AD) is an appealing technology for dairy farms because it stabilizes livestock manure while simultaneously producing energy in the form of biogas (50-70\% methane). The biogas can be used in a combined heat and power (CHP) cycle to supply farm energy demands, whereas surplus electricity can be sold back to the local power grid via net metering. Furthermore, through $\mathrm{AD}$, the nutrients (N, P, and $\mathrm{K}$ ) present in manure are mineralized and mostly conserved. Therefore, it is common to apply AD effluent (digestate) directly on agricultural land in place of raw manure or synthetic fertilizer. Finally, AD has many environmental benefits when compared with conventional manure management, including, for example, the reduction of odor and fewer greenhouse gas emissions (Ebner et al., 2015).

However, AD systems have high capital and operating costs, and these costs are difficult to recover in the United States due to low electricity and heat prices and the lack of economic incentives (e.g., capital grants for renewable energy, carbon credits; Gebrezgabher et al., 2010; Sanscartier et al., 2012). As a result, many $\mathrm{AD}$ operators rely on co-digestion of locally sourced organic wastes to provide additional revenue in the form of gate fees (Bishop and Shumway, 2009; Sanscartier et al., 2012). These organic wastes are typically more biodegradable than manure and, therefore, co-digestion 
should improve methane yields. In practice, however, the incentive to earn gate fees promotes using higher loading rates, which often has detrimental effects on the effectiveness of the $\mathrm{AD}$ process. In a recent study by Usack et al. (2018), high co-digestion loading rates were not only shown to reduce methane yields, but were also shown to induce considerably higher environmental emissions on the farm during downstream processes (e.g., digester effluent storage and land application). Therefore, alternative strategies to generate revenue, using $\mathrm{AD}$ as a platform technology, should be explored to help alleviate the dependence on gate fees and thereby promote better $\mathrm{AD}$ management.

In a review by Angenent et al. (2018), process heat from CHP was identified as an important but often underexploited resource in many AD applications. For example, most farm-based $\mathrm{AD}$ operations use only a fraction of the available process heat (i.e., 20-25\%) for digester heating (Poeschl et al., 2010), whereas the remaining heat is discarded via radiators. The problem is the limited demand for low-temperature heat on the farm or in surrounding (rural) areas. An alternative application of this surplus heat, then, could be the production of cooling energy via absorption refrigeration technology (ABR), because cooling is an important utility in dairy farming operations. For example, Upton et al. (2013) estimated that milk chilling and refrigeration constitute $31 \%$ of the total electricity demand on a dairy farm. Hypothetically, the surplus heat from CHP could drive an ABR system to generate cooling energy and replace electricity-driven refrigeration processes on the farm; this integrated process is referred to as combined cooling, heat, and power (CCHP).

When cooling energy from CCHP is used in place of electricity-driven refrigeration processes, this represents an avoided cost for the farm. However, given the low electricity prices in the United States, these savings may not be sufficient to recover the investment cost. For this reason, we explored an alternative application for the cooling energy, which involves conductively cooling cows to mitigate heat stress and increase milk production. We suspect that an increase in milk production could have a greater marginal return compared with electricity cost savings. In fact, we have already demonstrated that conductive cow cooling could be used to increase milk yields by $\sim 6 \%$ during heat stress conditions (Perano et al., 2015). In addition to the potential economic benefits of higher milk yields, we anticipated conductive cow cooling would have environmental benefits due to the large resource requirements of milk production.

Our main objective was to determine the environmental impact and economic feasibility of using CCHP on dairy farms to replace electricity-driven refrigeration processes and, when needed, to alleviate heat stress in dairy cattle via conductive cow cooling. Our secondary objective was to evaluate the specific effect of codigestion on the overall energy balance of the CCHP system compared with manure-only digestion.

\section{MATERIALS AND METHODS}

The research presented in the current study involves a synthesis of 2 previous studies conducted by our group. In the first study, we performed a controlled experiment to determine the effectiveness of conductive cow cooling as a technique to mitigate heat stress in dairy cattle (Perano et al., 2015). During the same study, we measured the power consumption and the heat transfer parameters of the conductive cow cooling units. These data allowed us to model a hypothetical conductive cow cooling system on a dairy farm. In the second study, we developed an environmental and economic life cycle assessment model to evaluate various co-digestion operation strategies. In the present study, we expanded this model by integrating an ABR process to simulate CCHP applications on the farm. A brief summary of the original model along with a description of the added conductive cow cooling system and ABR process is presented below. Further details pertaining to the original model can be found in Usack et al. (2018).

\section{Model Framework and Scenarios}

As a basis, we assumed a 1,000-cow dairy farm in Upstate New York, which uses AD and CHP for (1) the treatment of dairy manure and (2) the production of electricity with net metering. New York electricity generation by source comprised 39\% natural gas, $31 \%$ nuclear, $19 \%$ hydroelectric, $6 \%$ other renewable energy (wind, solar, biomass), $3 \%$ coal, and $2 \%$ petroleum (EIA, 2014). Therefore, the global warming potential $\left(\mathrm{kg} \mathrm{CO}_{2}-\right.$ equivalents) associated with the production of $1 \mathrm{kWh}$ of NYS electricity $\left(\mathbf{k W h} \mathbf{h}_{\mathbf{e}}\right)$ is approximately $3.77 \mathrm{E}^{-1}$ $\mathrm{kg}$ of $\mathrm{CO}_{2}$-equivalents. Heat captured by the $\mathrm{CHP}$ was used to heat the digester. The AD system was modeled as a single-stage, completely mixed digester operated at a temperature of $35^{\circ} \mathrm{C}$, a hydraulic retention time of $35 \mathrm{~d}$, and an organic loading rate of $1.81 \mathrm{~kg}$ of chemical oxygen demand $(\mathbf{C O D}) \cdot \mathrm{m}^{-3} \cdot$ day $^{-1}$. Chemical oxygen demand is the conventional assay used by wastewater treatment facilities to approximate the amount of organic material in a waste stream. Therefore, to establish a common basis of comparison for the different organic waste types used during co-digestion, we defined the life cycle assessment functional unit as the treatment of $1,000 \mathrm{~kg}$ of COD by anaerobic digestion. We evaluated 3 separate AD operation strategies: (1) manure-only 
digestion (i.e., base case); (2) co-digestion with kitchen waste; and (3) co-digestion with dissolved air flotation sludge. In the first co-digestion scenario, kitchen waste was blended with dairy manure at a COD mixture ratio of 1.75 (i.e., total organic loading rate $=5.16 \mathrm{~kg}$ of $\left.\mathrm{COD} \cdot \mathrm{m}^{-3} \cdot \mathrm{day}^{-1}\right)$, whereas in the second co-digestion scenario dissolved-air flotation sludge was blended at a COD mixture ratio of 2.5 (i.e., total organic loading rate $=6.34 \mathrm{~kg}$ of COD $\cdot \mathrm{m}^{-3} \cdot$ day $\left.^{-1}\right)$. According to Usack et al. (2018), these 2 COD mixture ratios resulted in the highest methane yields.

In addition, we assumed a project lifetime of $20 \mathrm{yr}$ for all infrastructure and equipment, except for the CHP system, where we assumed a 10-yr lifetime. For the life cycle boundary, we used a farm gate-to-farm gate approach, which excludes all life cycle processes associated with the production or consumption of energy, material, and monetary flows that occur outside the farm. For example, we did not include the life cycle emissions and costs associated with the production and transport of kitchen waste from the residential or commercial sector. Within the farm gate-to-farm gate boundary, we separately modeled 6 unit processes: (1) predigestion processing; (2) anaerobic digestion; (3) biogas utilization; (4) digestate storage; (5) land application; and (6) digestate export (Figure 1). Within the biogas utilization unit process, we evaluated 4 cooling scenarios: (1) CHP only; (2) CCHP + conductive cow cooling at low effectiveness; (3) CCHP + conductive cow cooling at high effectiveness; and (4) CCHP + substitution of electricity-driven refrigeration processes. For the conductive cow cooling scenarios, surplus cooling energy that was not used for conductive cow cooling (i.e., during the cold season, overnight, and on non-heat stress days) was used to displace electricity-driven refrigeration processes on the farm within demand limits (i.e., milk chilling/refrigeration, biogas inlet cooling). In the electricity-only scenario, we assumed infinite demand

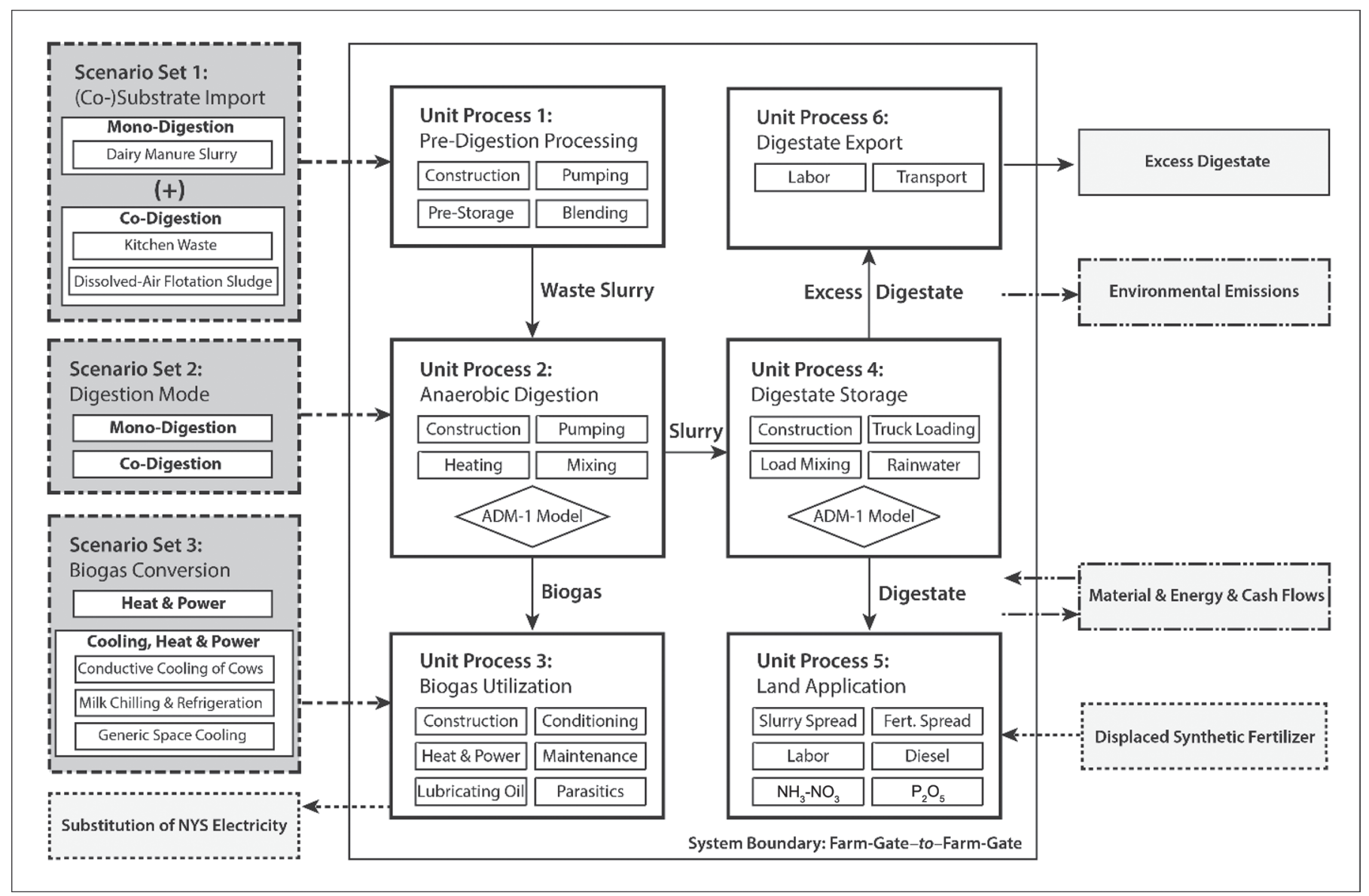

Figure 1. Environmental and economic life cycle model showing the system boundary, unit processes (bolded solid lines), subunit processes (inset solid lines), scenario sets (bolded dash-dot lines), New York State (NYS) electricity and synthetic fertilizer substitutions (dotted lines), and generic environmental and monetary flows (dash-dot arrows). ADM = anaerobic digestion model; Fert. = fertilizer. 
for cooling energy either on the farm or for auxiliary applications (e.g., residential air conditioning). In total, 12 distinct model scenarios were assessed in the study.

\section{Life Cycle Inventory}

The environmental life cycle inventory was assembled in SimaPro 8.1 (Pré North America Inc., Washington DC), using process data from EcoInvent v. 3.1 (Ecoinvent, Zurich, Switzerland) when available. Emissions, energy, and material flows of system processes directly influenced by scenario selection were separately modeled using either (1) the anaerobic digestion model \#1 (ADM1; i.e., anaerobic digestion and digestate storage unit processes) or (2) values derived from literature (i.e., all remaining unit processes; Table A1). The ADM1 is a dynamic, process-based model that uses differential and algebraic equations to simulate mass and energy flows in the AD process (Batstone et al., 2002a). Feedstock composition and ADM1 input parameters were taken directly from the literature (Table 1).

The economic life cycle inventory included all major capital items (e.g., infrastructure and equipment) and monetary flows, including revenue streams from electricity, fertilizer, milk, and gate fee revenues and cost streams from materials (e.g., engine lubrication oil, diesel, commercial fertilizer) and nonmaterial costs (e.g., maintenance, labor, indirect, and insurance costs; Table A1). All monetary flows were normalized using cost index values derived from the Chemical Engineering Plant Cost Index.

\section{Environmental Impact and Economic Feasibility Assessments}

The environmental impact assessment was conducted in SimaPro software using IMPACT $2002^{+}$v. 2.12 methodology, which includes both midpoint and endpoint impact categories (Jolliet et al., 2003). For the purposes of our study, we only reported the impact categories that exhibited significant differences between scenarios. These included all the endpoint categories - climate change, ecosystem quality, human health, resources, and human health - and only 1 midpoint category, land occupation. We compared economic feasibility, using an after tax, net present value analysis, assuming a discount rate of $15 \%$. In addition, we applied the US Federal Modified Acceleration Cost Recovery System

Table 1. Feedstock composition and anaerobic digestion model \#1 input parameters

\begin{tabular}{|c|c|c|c|c|}
\hline Feedstock material & Units & $\begin{array}{l}\text { Dairy manure } \\
\text { slurry }\end{array}$ & $\begin{array}{l}\text { Kitchen } \\
\text { waste }\end{array}$ & $\begin{array}{l}\text { Dissolved air } \\
\text { floatation sludge }\end{array}$ \\
\hline $\mathrm{TS}$ & $\%$ & $6.10^{1}$ & $29.10^{2}$ & $36.00^{3}$ \\
\hline Volatile solids & $\%$ & $5.00^{1}$ & $26.00^{2}$ & $35.3^{3}$ \\
\hline Total phosphorus & $\mathrm{kg}$ of $\mathrm{P} \cdot \mathrm{m}^{-3}$ & $0.55^{5}$ & $1.61^{2}$ & $0.05^{3}$ \\
\hline Particulate composites & $\mathrm{kg}$ of chemical oxygen demand $(\mathrm{COD}) \cdot \mathrm{m}^{-3}$ & $2.21^{1}$ & $0.00^{2}$ & $0.00^{3}$ \\
\hline Particulate inerts & $\mathrm{kg}$ of $\mathrm{COD} \cdot \mathrm{m}^{-3}$ & $19.65^{1}$ & $6.97^{2}$ & $262.70^{3}$ \\
\hline Particulate lipids & $\mathrm{kg}$ of COD $\cdot \mathrm{m}^{-3}$ & $6.77^{1}$ & $58.38^{2}$ & $768.50^{3}$ \\
\hline Short-chain fatty acids & $\mathrm{kg}$ of $\mathrm{COD} \cdot \mathrm{m}^{-3}$ & $1.53^{1}$ & $8.75^{2}$ & $0.70^{3}$ \\
\hline Soluble AA & $\mathrm{kg}$ of COD $\cdot \mathrm{m}^{-3}$ & $1.80^{6}$ & $3.92^{2}$ & $0.57^{3}$ \\
\hline Soluble fatty acids & $\mathrm{kg}$ of $\mathrm{COD} \cdot \mathrm{m}^{-3}$ & $0.53^{6}$ & $1.94^{2}$ & $2.70^{3}$ \\
\hline Soluble sugars & $\mathrm{kg}$ of $\mathrm{COD} \cdot \mathrm{m}^{-3}$ & $0.00^{1}$ & $5.87^{2}$ & $0.48^{3}$ \\
\hline Soluble inerts & $\mathrm{kg}$ of $\mathrm{COD} \cdot \mathrm{m}^{-3}$ & $3.79^{6}$ & $0.23^{2}$ & $0.92^{3}$ \\
\hline Inorganic carbon & $\mathrm{mol} \cdot \mathrm{L}^{-1}$ & $0.062^{2}$ & $0.04^{2}$ & $0.05^{7}$ \\
\hline Lipid hydrolysis rate & $1 \cdot \mathrm{d}^{-1}$ & $0.31^{9}$ & $1.24^{2}$ & $1.04^{3}$ \\
\hline
\end{tabular}

${ }^{1}$ Labatut, 2012.

${ }^{2}$ Zaher et al., 2009.

${ }^{3}$ Astals et al., 2014.

${ }^{4}$ Usack and Angenent, 2015.

${ }^{5}$ Angelidaki et al., 1999.

${ }^{6}$ Zhou et al., 2011.

${ }^{7}$ Song et al., 2004.

${ }^{8}$ Batstone et al., 2002b.

${ }^{9}$ Lübken et al., 2007. 
(Internal Revenue Service, 2018) to account for depreciation of capital assets, assuming an income tax rate of $38 \%$. Technical, environmental, and economic parameter uncertainty ranges were generated by Monte Carlo simulation using composite probability distributions originally derived from literature values (Table A1).

\section{Subprocess: Combined Cooling, Heat, and Power System}

We assumed that all the recovered biogas was used by the CHP with net metering. On-farm electricity offsets were valued at $\$ 0.152 \cdot \mathrm{kWh}^{-1}$, whereas surplus CHP electricity returned to the New York State (NYS) electric grid was valued at $\$ 0.03 \cdot \mathrm{kWh}^{-1}$ (EIA, 2014). Electricity offsets represent the average daily price of electricity. Time-of-use electricity prices were not applied because instantaneous power consumption data could not be collected. The 2014 fiscal year was selected as the basis for the economic analysis to correspond with the environmental field data collected during the conductive cow cooling experiment (Perano et al., 2015). Since 2014, NYS electricity prices have not changed substantially in the commercial sector; in August 2018, the electricity price was valued at $\$ 0.155 \cdot \mathrm{kWh}^{-1}$ (EIA, 2018). The heat captured as hot water from the CHP cooling jacket and exhaust recuperator was first used to supply heating to the digester vessel (only), and all remaining heat was used to power a single-stage, singleeffect ABR cycle. Lithium bromide-water served as the working pair solution of the ABR, and the chilled fluid exit temperature was $7^{\circ} \mathrm{C}$. The capacity of the ABR system for each scenario was determined by estimating the coefficient of performance (COP; i.e., $\sim 0.65$ ) at standard conditions as outlined by the American Society of Heating, Refrigerating and Air-Conditioning Engineers and by assuming a hot water supply temperature of $115^{\circ} \mathrm{C}$ (ASHRAE, 1995). Finally, we assumed an average $\mathrm{COP}$ of 3.0 for all electricity-driven refrigeration processes (ASHRAE, 1995).

\section{Subprocess: Conductive Cow Cooling System}

We modeled heat stress levels based on the NYS climate, which corresponds to $715 \mathrm{~h}$ of heat stress per year (St-Pierre et al., 2003). New York State has a mild heat stress climate compared with more southern states, such as Texas, which experiences approximately $3,185 \mathrm{~h} \cdot \mathrm{yr}^{-1}$ of heat stress (St-Pierre et al., 2003). We assumed heat stress onset occurs at a temperaturehumidity index of 70 , which when exceeding $6 \mathrm{~h} \cdot \mathrm{d}^{-1}$, causes a milk yield reduction of $6 \%$ relative to baseline production yields (Perano et al., 2015). However, when conductive cow cooling is applied, we assumed heat stress was effectively mitigated. Baseline milk yields were determined using the Integrated Farm Systems Model v. 4.1 (Rotz, 2012) by applying the default parameters assigned to this region. In the low-effectiveness scenario, we estimated the heat energy requirements using a cooling demand of $1.435 \mathrm{~kW} \cdot \mathrm{bed}^{-1}$, which was based on the empirical data collected in Perano et al. (2015). The high-effectiveness scenario was modeled assuming a cooling demand of $0.400 \mathrm{~kW} \cdot \mathrm{bed}^{-1}$, which was derived from the heat conduction model developed by Gebremedhin et al. (2016) for a chilled water temperature of $7^{\circ} \mathrm{C}$. Additional details regarding the CHP, $\mathrm{ABR}$, and conductive cow cooling system are available in the appendix (Table A1).

\section{RESULTS AND DISCUSSION}

\section{Co-Digestion Increases the Net Energy Balance Compared with Manure-Only Digestion}

Dairy manure is less biodegradable and has a lower COD concentration (i.e., $\sim 60 \mathrm{~kg}$ of $\mathrm{COD} \cdot \mathrm{m}^{-3}$ ) compared with kitchen waste $\left(\sim 380 \mathrm{~kg}\right.$ of $\left.\mathrm{COD} \cdot \mathrm{m}^{-3}\right)$ and dissolved-air flotation sludge $\left(\sim 1,050 \mathrm{~kg}\right.$ of $\mathrm{COD} \cdot \mathrm{m}^{-3}$; Table 1, Figure A1). The high lignin content in dairy manure, which can be considered biologically unavailable or inert to $\mathrm{AD}$, is mostly responsible for its lower biodegradability (Figure A1). This means that a relatively smaller fraction of the OM is available for methane production compared with other, more biodegradable wastes. Furthermore, a lower COD concentration indicates that the $\mathrm{OM}$ is more dilute, which ultimately results in a lower average retention time within the digester at a given COD loading rate. Consequently, specific methane yields $\left(\mathrm{m}^{3}\right.$ of $\mathrm{CH}_{4} \cdot \mathrm{kg}$ of $\left.\mathrm{COD}^{-1}\right)$ and COD removal efficiency from the AD process are reduced. Another important consequence of a lower COD concentration is that more parasitic energy is consumed (e.g., electricity for mixing and pumping, heat for digester heating) compared with a feedstock with a higher COD concentration. Ultimately, the low biodegradability and COD concentration of dairy manure leads to less net energy for use in CHP or CCHP, as less methane is produced and greater parasitic energy losses occur per kilogram of COD (Figure 2, Table A2).

Unlike dairy manure, dissolved-air flotation sludge is very biodegradable and has a high COD concentration. Dissolved-air flotation sludge is composed mostly of lipids ( $>70 \%$, COD basis), with a small fraction of proteins $(<2 \%)$ and virtually no carbohydrates (Figure A1). On a weight basis, lipids have appreciably higher methane production potential $\left(0.99 \mathrm{~m}^{3} \cdot \mathrm{kg}^{-1}\right)$ compared with proteins $\left(0.63 \mathrm{~m}^{3} \cdot \mathrm{kg}^{-1}\right)$ and carbohydrates $(0.42$ $\mathrm{m}^{3} \cdot \mathrm{kg}^{-1}$; Alves et al., 2009). As a result, co-digestion 
with dissolved-air flotation sludge suffered the least parasitic energy loss through the biogas plant (14\% of total electricity, $18 \%$ of total heat; Figure 2, Table A2). Kitchen waste performed similarly well, with $18 \%$ lost as parasitic electricity and $24 \%$ as parasitic heat. Manure-only digestion performed markedly worse with 54 and $68 \%$ lost as parasitic electricity and heat, respectively. Therefore, to improve the energy balance, farm $\mathrm{AD}$ operators should take measures to increase the organic strength of dairy manure by minimizing process water inputs during manure collection and prestorage.

The maximum specific methane yield predicted by ADM1 was greater for kitchen waste $\left(252 \mathrm{~m}^{3}\right.$ of $\mathrm{CH}_{4} \cdot \mathrm{kg}$ of $\left.\mathrm{COD}^{-1}\right)$ than for dissolved-air flotation sludge $(225$ $\mathrm{m}^{3}$ of $\mathrm{CH}_{4} \cdot \mathrm{kg}$ of $\mathrm{COD}^{-1}$ ) and dairy manure (Table A2). The higher specific methane yield of kitchen waste compensated for its greater parasitic energy loss ( $21 \%$ of total energy captured by CHP) compared with dissolved-air flotation sludge $(16 \%)$, resulting in a slightly greater net energy balance for electricity, heat, and cooling (Figure 2). In both co-digestion scenarios, the amount of cooling power made available via CCHP was more than double that of manure-only digestion. It is worth noting that, if $\mathrm{AD}$ is coupled to hydrothermal processing, the unconverted fraction of biomass effluent resulting from $\mathrm{AD}$ could be further liquefied to bio-oils or gasified to syngas to achieve much higher energy recovery (Gerber Van Doren et al., 2017; Posmanik et al., 2018).

Finally, in all scenarios, the $\mathrm{AD}$ process stage had the greatest parasitic energy demand $(\sim 80 \%$ of total parasitic energy) compared with the parasitic energy

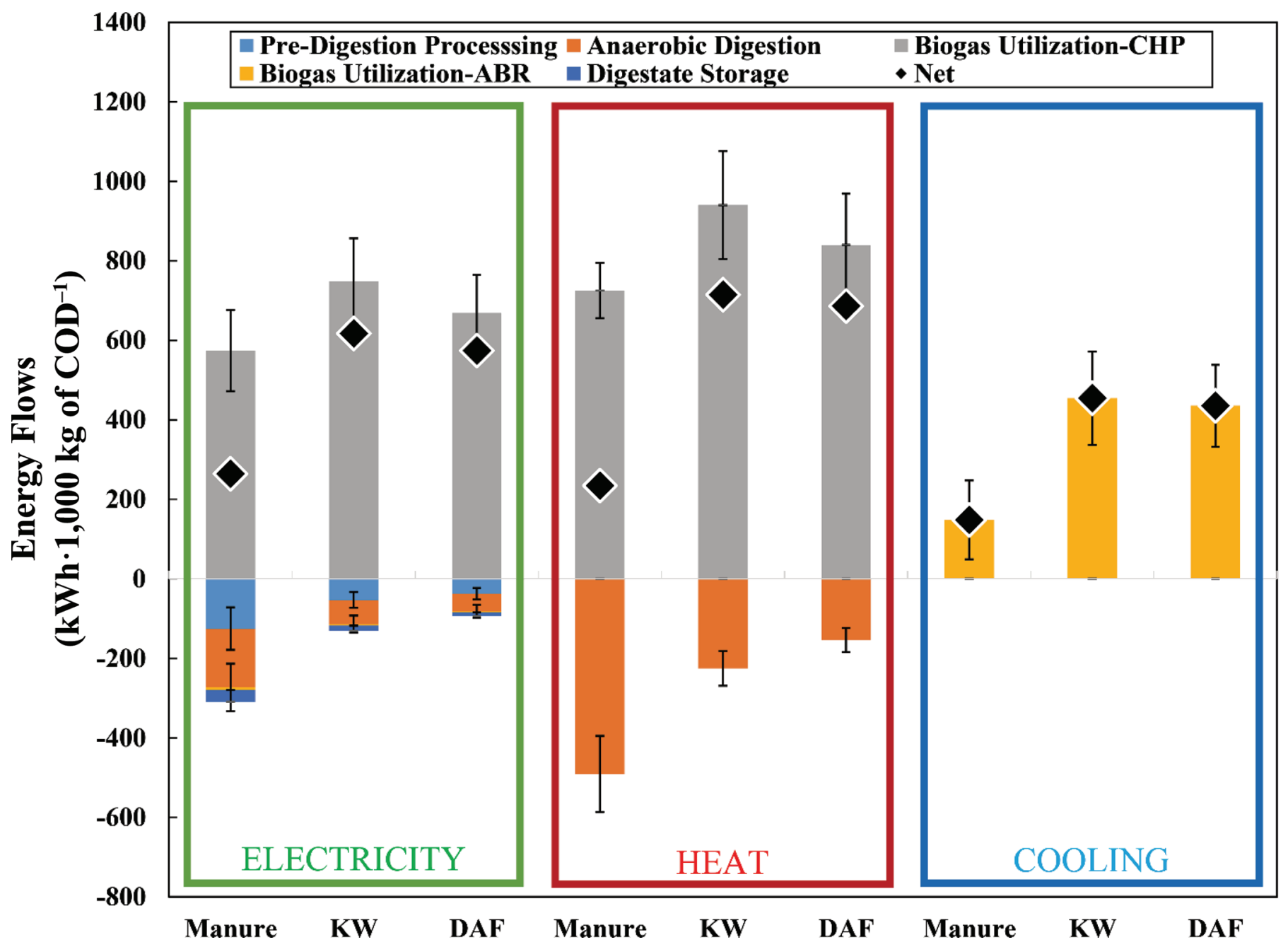

Figure 2. Production and parasitic losses of electricity, heat, and cooling along the biogas plant for manure-only and co-digestion (i.e., KW and DAF) scenarios. The biogas utilization process was divided into 2 subprocesses: (1) combined heat and power (CHP) and (2) absorption refrigeration (ABR). Net energy flows (production minus parasitic losses) is indicated using black diamonds. COD = chemical oxygen demand; $\mathrm{DAF}=$ dissolved-air flotation sludge; $\mathrm{KW}=$ kitchen waste. Error bars represent SD of the modeled uncertainty. 
demand of all other processes (Figure 2). This process stage requires energy for digester mixing, pumping, and digester heating. Predigestion processing, which involves influent blending or pumping and prestorage tank mixing, constituted the next largest parasitic electricity demand ( $15 \%$; Figure 2$)$. Parasitic electricity required for digestate storage mixing (during truck loading) and ABR operation were relatively insignificant $(<5 \%$, combined $)$ compared with all other life cycle processes.

\section{Co-Digestion Is Responsible for the Greatest Reduction in Life Cycle Environmental Impacts}

Co-digestion with kitchen waste and dissolved-air flotation sludge significantly reduced environmental and health impacts throughout the farm AD life cycle (Figure 3). These impact reductions were caused mainly by (1) attenuating background farm emissions and (2) displacing additional NYS electricity and synthetic fertilizers. Background farm emissions are those that arise from routine, conventional dairy farming practices, such as temporary manure storage and land application. For example, many farms cultivate their own feed crops by spreading raw manure (or manure digestate) as an organic fertilizer, which induces environmental emissions (e.g., ammonia, phosphate). As co-digestion of kitchen waste and dissolved-air flotation sludge contribute considerably more COD compared with manure-only digestion (Figure A1.B), this led to reductions in background farm emissions proportional to the applied loading rate. The greatest reductions occurred during land application ( $>60 \%$ reduction compared with manure-only digestion, single-score basis), where background emissions were the highest (Figure 3). Similarly high environmental impact reductions $(\sim 60 \%)$ occurred at the predigestion process stage, where open-air mixing in the storage tank generated high ammonia emissions (i.e., $0.024 \mathrm{~kg}$ of $\mathrm{NH}_{3}-\mathrm{N} \cdot \mathrm{kg}^{-1}$ of total N; Figure 3).

In this model, the amount of nitrogen available in the manure-only scenario was not sufficient to satisfy
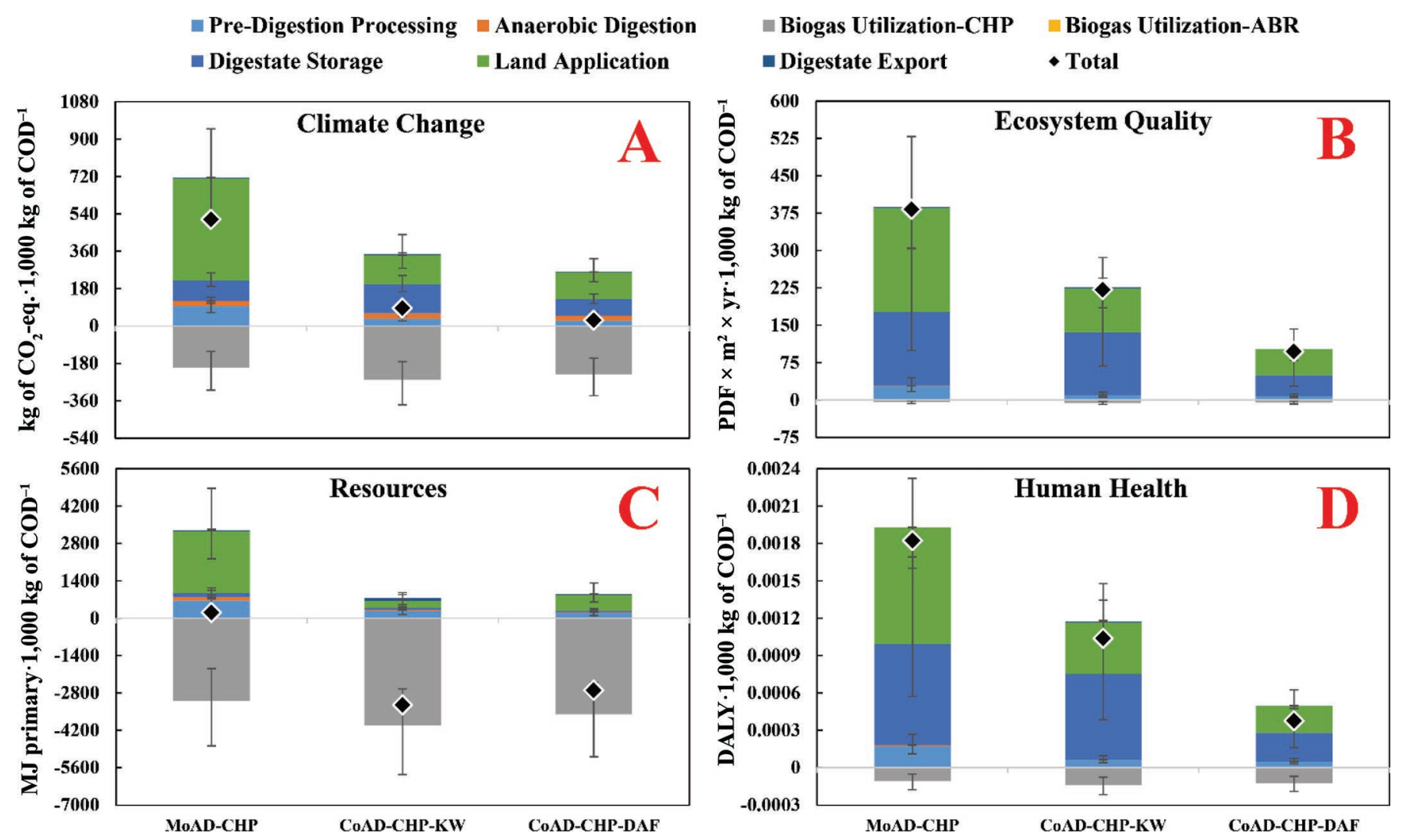

Figure 3. Environmental and health effects at the damage level determined with IMPACT 2002+ (Jolliet et al., 2003) for each of the combined heat and power (CHP)-only scenarios at each process stage. The environmental damage categories included (A) climate change, (B) ecosystem quality, $(\mathrm{C})$ resources, and $(\mathrm{D})$ human health. Eq. = equivalents; $\mathrm{ABR}=$ absorption refrigeration; $\mathrm{CoAD}=$ co-digestion; $\mathrm{COD}=$ chemical oxygen demand; DAF = dissolved-air flotation sludge; DALY = daily adjusted life years; MoAD = manure-only digestion; KW = kitchen waste; PDF = potentially disappeared fraction of species. Error bars represent the $95 \%$ CI of the modeled uncertainty distribution. 
crop demands; therefore, commercial nitrogen fertilizer (as ammonium nitrate) was needed in addition to the digestate. However, $100 \%$ of the crop $\mathrm{N}$ demands were met during co-digestion using kitchen waste, which contains $15.3 \mathrm{~kg}$ of $\mathrm{N} \cdot \mathrm{m}^{-3}$. Dissolved-air flotation sludge, which contains less nitrogen $\left(1.2 \mathrm{~kg}\right.$ of $\left.\mathrm{N} \cdot \mathrm{m}^{-3}\right)$, replaced $\sim 90 \%$ of the required ammonium nitrate fertilizer. This displaced fertilizer contributed, in small part, to the reductions in climate change, ecosystem quality, and human health impact categories (Figure 3). However, it constituted the greatest reductions in resources (Figure 3 ), as production of ammonium nitrate (via the HaberBosch process) requires large inputs of primary energy. In the manure-only scenario, ammonium-nitrate inputs accounted for $\sim 80 \%$ of the primary resource impacts at the land application process stage. Moreover, because kitchen waste had higher nitrogen content per COD compared with dissolved-air flotation sludge, kitchen waste led to greater reductions in the resource impact category. This was the only impact category where codigestion with kitchen waste led to greater total reductions compared with dissolved-air flotation (Figure 3).

Co-digestion also resulted in greater displacement of NYS electricity (represented at the stage Biogas Utilization-CHP in Figure 3), which also induced significant environmental impact reductions. As fossil fuels comprise approximately $40 \%$ of the NYS electricity mix (EIA, 2014), the greatest reductions from displaced electricity occurred in the climate change and resource categories (Figure 3). Moreover, because kitchen waste had a higher specific methane yield compared with dissolved-air flotation sludge, kitchen waste co-digestion resulted in proportionally greater reductions in these impact categories. Finally, climate change impacts were further reduced via co-digestion of dissolved-air flotation sludge at the digestate storage process; however, this was not the case for kitchen waste co-digestion, which resulted in greater climate change impacts compared with manure-only digestion (Figure 3 ). This was caused by differences in residual methane and $\mathrm{N}_{2} \mathrm{O}$ emissions from digestate storage.

Both co-digestion scenarios, due to their higher loading rate, induced greater residual methane emissions and climate change impacts compared with manureonly digestion. Interestingly, kitchen waste induced proportionally more residual methane emissions $(110 \%$ increase compared with manure-only) than dissolvedair flotation sludge (34\% increase), even though kitchen waste had a higher specific methane yield and COD removal efficiency. Although counterintuitive, this is explained by the lower biodegradability of dissolved-air flotation sludge, which suggests the removal of degradable COD during dissolved-air flotation sludge co- digestion was greater than kitchen waste co-digestion, even though removal of total COD was less.

The disparity in climate change impacts between dissolved-air flotation sludge and kitchen waste were further widened by the degree of $\mathrm{N}_{2} \mathrm{O}$ reductions at the digestate storage stage. Both kitchen waste and dissolved-air flotation sludge contain less nitrogen per COD compared with dairy manure, which explains the net $\mathrm{N}_{2} \mathrm{O}$ reductions. However, in the case of dissolvedair flotation sludge, the COD-to-nitrogen ratio was sufficiently high that most of the available nitrogen (i.e., ammonium) was immobilized via biomass growth, which limited the amount of nitrogen available for $\mathrm{N}_{2} \mathrm{O}$ formation. This resulted in a $70 \% \mathrm{~N}_{2} \mathrm{O}$ reduction during dissolved-air flotation co-digestion, whereas kitchen waste only achieved a $1 \% \mathrm{~N}_{2} \mathrm{O}$ reduction.

\section{CCHP Reduces Environmental Impacts by Preventing Milk Production Losses and Saving Power}

Although co-digestion was responsible for the greatest environmental impact reductions, CCHP further reduced life cycle emissions relative to those scenarios involving only CHP (Figure 4). By preventing dairy milk production losses, conductive cow cooling scenarios induced considerable reductions in all impact categories. As CCHP was also used to displace electricity-driven refrigeration processes (e.g., milk chilling and refrigeration) during periods of no heat stress, additional impact reductions were accrued. However, substituted electricity often contributed less to overall reductions compared with milk production, especially for co-digestion and high-effectiveness conductive cow cooling scenarios (Figure 4). The exception occurred for the manure-only digestion and low-effectiveness cow-cooling scenarios, where the least amount of cooling energy was available. In those scenarios, only $4.2 \%$ of the 1,000-cow herd was supplied with cooling. During kitchen waste and dissolved-air flotation sludge co-digestion scenarios, however, this figure increased to 36.8 and $45.7 \%$, respectively. The cooling supply could be further increased with the application of higher co-digestion mixture ratios. For example, if the AD operator were to apply the maximum mixture ratio of kitchen waste (i.e., 5.95:1, total organic loading rate $=$ $12.6 \mathrm{~kg}$ of $\mathrm{COD} \cdot \mathrm{m}^{-3} \cdot$ day $^{-1}$ ) or dissolved-air flotation sludge (i.e., 6.50:1, total organic loading rate $=13.6$ $\mathrm{kg}$ of $\mathrm{COD} \cdot \mathrm{m}^{-3} \cdot$ day $^{-1}$; Usack et al., 2018), the CCHP system could supply 86.7 and $96.2 \%$ of the herd with conductive cow cooling, respectively.

These are promising figures given that conductive cow cooling is an emerging technology with consider- 

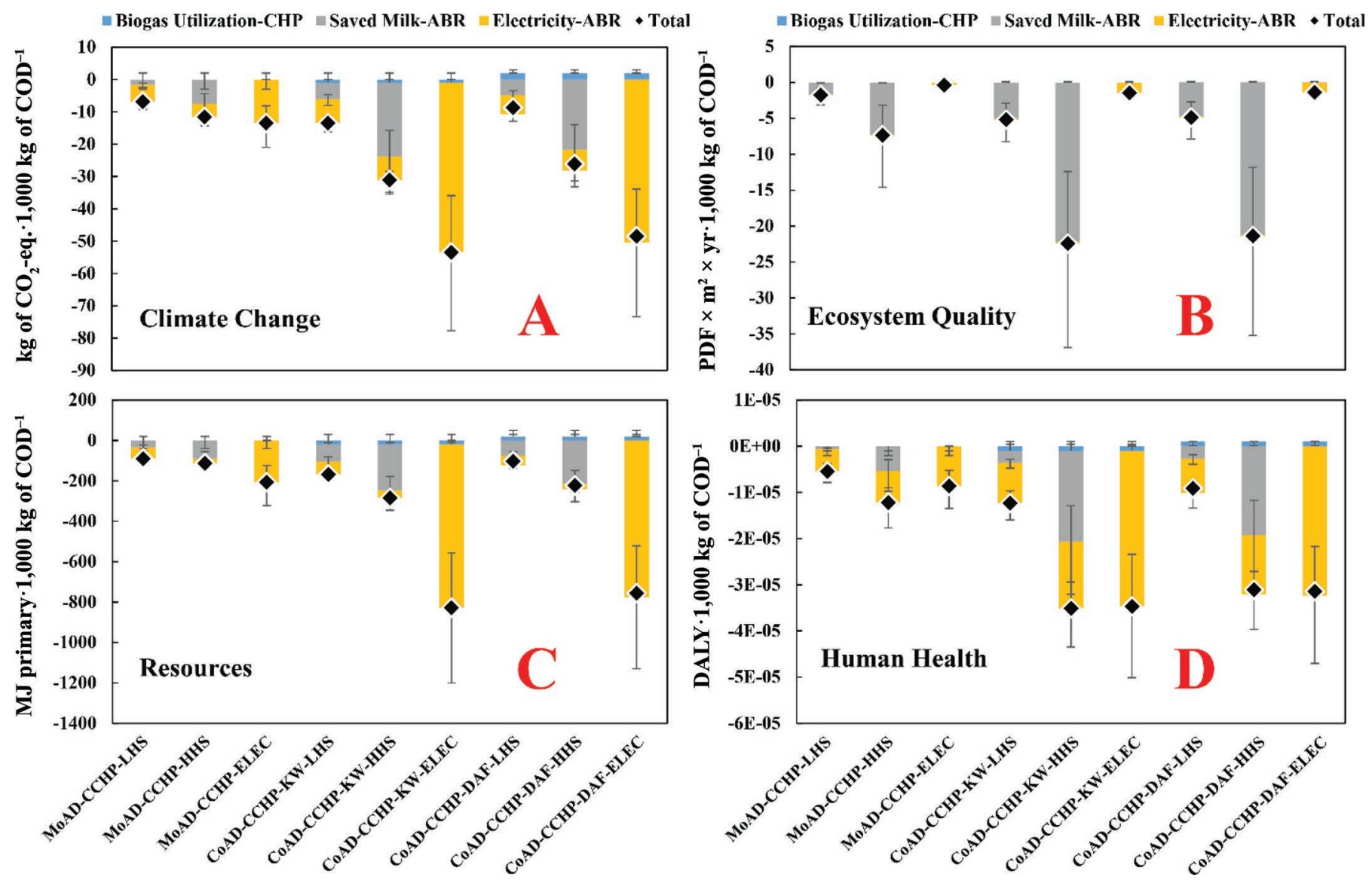

Figure 4. Environmental impact reductions induced by combined cooling, heat, and power (CCHP) through milk and electricity substitution relative to its corresponding combined heat and power (CHP) scenario. The environmental damage categories were assessed using IMPACT 2002+ (Jolliet et al., 2003) and included (A) climate change, (B) ecosystem quality, (C) resources, and (D) human health. Eq. = equivalents; $\mathrm{ABR}=$ absorption refrigeration; $\mathrm{CoAD}=$ co-digestion $; \mathrm{COD}=$ chemical oxygen demand; $\mathrm{DAF}=$ dissolved-air flotation sludge; $\mathrm{DALY}=$ daily adjusted life years; ELEC = electricity-only production; HHS = high-effectiveness conductive cow cooling; KW = kitchen waste; LHS = loweffectiveness conductive cow cooling; MoAD = manure-only digestion; PDF = potentially disappeared fraction of species. Error bars represent the $95 \%$ CI of the modeled uncertainty distribution.

able room for technical improvement. We assumed a rather high cooling load of $1.435 \mathrm{~kW} \cdot \mathrm{bed}^{-1}$ for the low-effectiveness scenarios based on preliminary data collected from the prototype conductive cow cooling system (Perano et al., 2015). The heat conduction efficiency in these prototypes, however, was not optimized. In a subsequent study by Gebremedhin et al. (2016), additional thermal physical property data were used to develop a heat conduction model that uses computational fluid dynamics to determine the theoretical heat flux through the cow waterbeds. This analysis suggested that the energy demand could be decreased considerably to a value approaching $\sim 0.400$ $\mathrm{kW}$ for cooling. bed $^{-1}$. When applying this value in the high-effectiveness conductive cow cooling scenarios, we observed that co-digestion with kitchen waste and dissolved-air flotation sludge could easily supply the entire herd with conductive cow cooling.
Moreover, within the high-effectiveness scenarios, environmental impact reductions from conductive cow cooling were considerably greater than from the substitution of electricity-driven refrigeration processes (Figure 4). This result can be attributed to the high resource inputs associated with milk production and the relatively low COP of absorption refrigeration (COP $=0.65 ; 0.65 \mathrm{kWh}$ of cooling per $\mathrm{kWh}$ of heat-energy supplied) compared with electricity-driven refrigeration cycles $(\mathrm{COP}=3.0 ; 3.0 \mathrm{kWh}$ of cooling per $\mathrm{kWh}$ of electrical-energy supplied). This difference in COP means that, in conventional refrigeration, $3 \mathrm{kWh}$ of cooling is delivered per kilowatt-hour of electricity supplied. In absorption refrigeration, $3 \mathrm{kWh}$ of conductive cow cooling would require $4.6 \mathrm{kWh}$ of heat; however, if the $4.6 \mathrm{kWh}$ of heat from the biogas was used to generate the electricity needed for the conventional refrigeration cycle, the situation is different. The conversion of heat 
into electricity is only about $25 \%$ efficient, which means that about $1.2 \mathrm{kWh}$ of electricity could be produced. With a COP of 3.0, if we used all the electricity produced to drive the compressive refrigeration system, this would amount to about $3.6 \mathrm{kWh}$ of cooling, slightly greater than $3.0 \mathrm{kWh}$. Yet, even with a lower overall effectiveness with respect to energy transfer, the environmental reductions per kilowatt-hour of conductive cow cooling using absorption refrigeration were often greater than displacing $1 \mathrm{kWh}$ of NYS electricity.

Nonetheless, due to the relatively high environmental impacts associated with NYS electric power production, the electricity-only scenarios also resulted in considerable reductions in climate change, resources, and human health impact categories (Figure 4). Moreover, the electricity-only scenario analysis indicates that the cooling load generated by CCHP greatly exceeds all the potential cooling demands on the farm (i.e., milk chilling/refrigeration, biogas inlet cooling). For the manure-only scenario, the cooling demands for milk refrigeration or chilling and biogas inlet cooling consumed 37.4 and $32.8 \%$ of the total cooling load generated by CCHP, respectively. Whereas for kitchen waste co-digestion, milk refrigeration or chilling and biogas inlet cooling required 4.3 and $29.8 \%$, respectively, and for dissolved-air flotation sludge these cooling demands dropped to 3.4 and $25.0 \%$.

\section{Feasibility of CCHP Requires Further Improvement and Higher Electricity Prices}

The cash flows associated with the ABR and conductive cow cooling system represented a minor fraction $(<5 \%)$ of the overall life cycle cost of the farm biogas plant in each CCHP scenario (Figure 5). The majority of costs associated with the biogas plant stemmed from the capital and operational expenses of the digester and CHP, whereas gate fees contributed the majority of revenue. Electric power production from CHP only contributed a minor fraction to total revenue, and therefore electricity from CCHP was even less significant.

When looking at the costs and revenue flows of CCHP scenarios specifically, we observed that neither conductive cow cooling nor electricity substitution was economically viable (Figure 5B). In the suggested CCHP application, the heat supply was effectively free as it was supplied by the produced biogas, and yet the value of electricity produced was not sufficient to recoup the capital cost of the ABR system. The CCHP with codigestion provided considerably more heat energy and other technical benefits from an improved economy of scale compared with manure-only digestion. However, because of the wholesale electricity price penalty of net metering, these scenarios also could not achieve economic viability. According to our model, the electricity price (without conductive cow cooling included) would need to be $\$ 0.312 \cdot \mathrm{kWh}^{-1}$ for manure-only digestion, $\$ 0.095 \cdot \mathrm{kWh}^{-1}$ for kitchen waste co-digestion, and $\$ 0.086 \cdot \mathrm{kWh}^{-1}$ for dissolved-air flotation sludge codigestion to make CCHP on farms economically viable. For these reasons, displaced electricity from CCHP cannot totally replace co-digestion and gate fees as an alternative source of revenue.

The conductive cow cooling scenarios were more lucrative than electricity-only scenarios. Even under the low-effectiveness scenarios, the value of $1 \mathrm{kWh}$ of cooling used for conductive cow cooling was $\$ 0.049$, compared with $\$ 0.01$ per $\mathrm{kWh}$ of cooling used to produce wholesale electricity. This figure would increase to $\$ 0.17$ per $\mathrm{kWh}$ of cooling under the high-effectiveness scenarios, which is greater than the premium electricity price in most states. For dissolved-air flotation sludge co-digestion, only a $40 \%$ further improvement in conductive cow cooling effectiveness would be necessary to break even, whereas a $55 \%$ improvement would be required for kitchen waste. This could be achieved either through further increases in milk yield or reductions in heat demand by the conductive cow cooling system. Under the manure-only scenario, economic viability would be technically unattainable in NYS and would require additional market improvements, such as reduced ABR capital costs, renewable energy incentives or credits, higher milk prices, or higher frequency of heat stress events.

\section{Outlook}

Although we observed pertinent reductions in environmental impacts in all $\mathrm{AD}$ and CCHP scenarios and considerable reductions in land occupation when conductive cow cooling was applied, not one of the CCHP scenarios was economically viable. Thus, at present, CCHP cannot alleviate the dependence of $\mathrm{AD}$ on co-digestion and gate fees. However, conductive cow cooling is a nascent technology with considerable room for technical improvement, which could make it economically feasible in the near future. Most importantly, for the CCHP scenario with cow cooling, climate is a very important factor. Heat stress frequency in NYS is relatively low (i.e., $715 \mathrm{~h} \cdot \mathrm{yr}^{-1}$ ) compared with other parts of the United States, such as Texas, which experiences approximately $3,000 \mathrm{~h}$ of heat stress annually (St-Pierre et al., 2003). This means less opportunity exists in NYS to generate milk revenue with conductive cow cooling compared with climates with high annual heat stress levels. Therefore, CCHP with conductive 

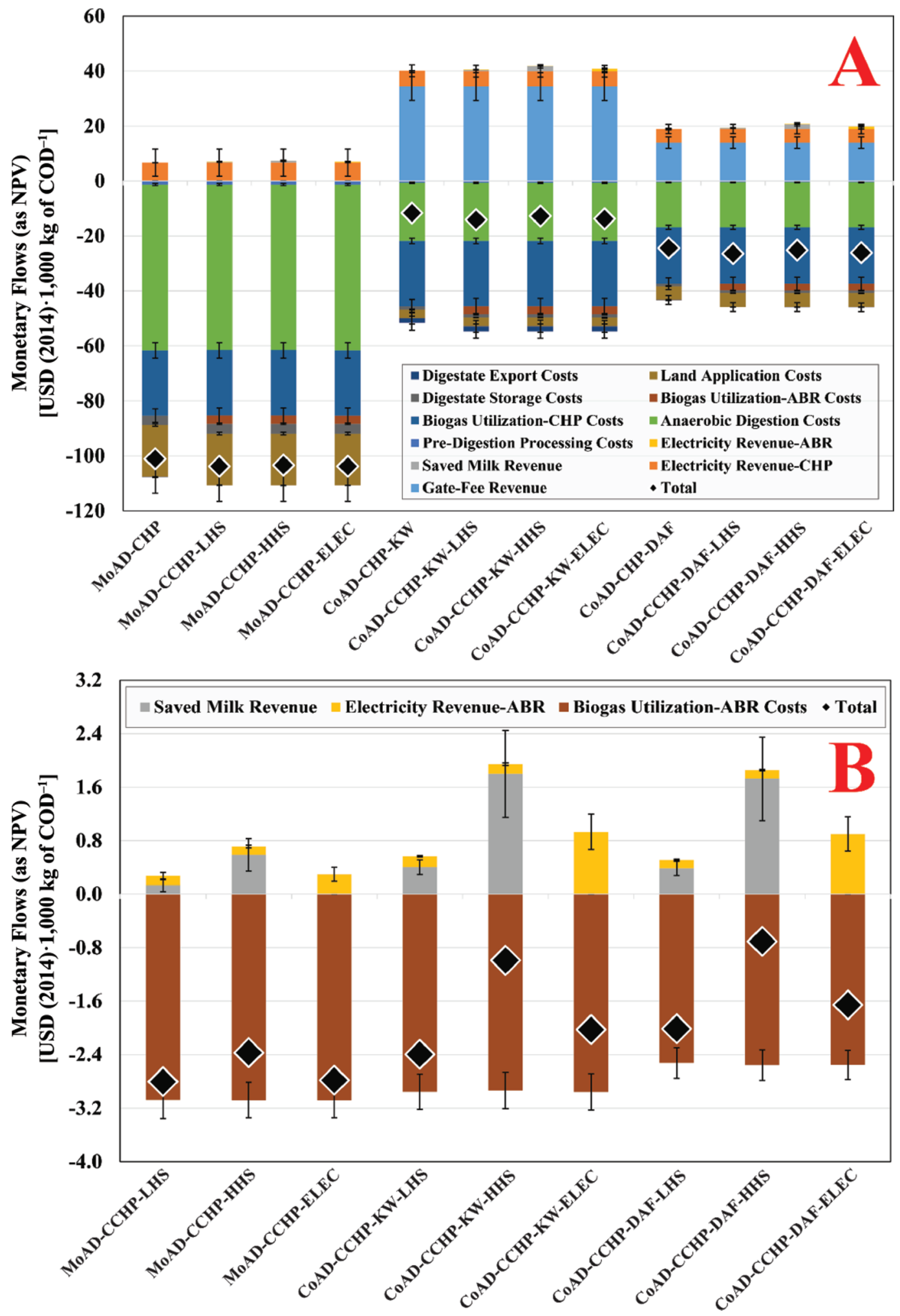

Figure 5. Total monetary flows [as net present value (NPV)] of the biogas plant according to process stage (A). Cost and revenue streams (as NPV) induced by combined cooling, heat, and power (CCHP) through milk and electricity substitution relative to its corresponding combined heat and power $(\mathrm{CHP})$ scenario $(\mathrm{B}) . \mathrm{ABR}=$ absorption refrigeration; $\mathrm{CoAD}=$ co-digestion; $\mathrm{COD}=$ chemical oxygen demand; $\mathrm{DAF}=$ dissolved-air flotation sludge; ELEC = electricity-only production; HHS = high-effectiveness conductive cow cooling; KW = kitchen waste; LHS $=$ low-effectiveness conductive cow cooling; MoAD = manure-only digestion; USD = United States dollars. Error bars represent the $95 \%$ CI of the modeled uncertainty distribution. 
cow cooling may already be economically viable in warmer climates. However, a new study for the specific conditions of dairy farms at these locations would be necessary to verify this.

In addition, in our analysis, we only considered the economic benefit associated with increased milk revenue through conductive cow cooling. Other indirect economic benefits associated with heat-stress mitigation exist, although they are more difficult to quantify. For example, heat stress in dairy cattle also results in decreased DMI (Collier et al., 1982; Perano et al., 2015), increased standing time (Cook et al., 2007), reduced birthing success (Collier et al., 2006; Norman et al., 2012), and increased incidence of cattle disease (Liu et al., 2014) and mortality (Stull et al., 2008). All of these factors have an economic cost. If these costs were accounted for in our study, CCHP with conductive cow cooling would be more lucrative from an economic point of view.

Finally, we need to consider the potential impacts of future climate change on the frequency and severity of heat stress. Additionally, we can expect that energy prices as well as environmental incentives for cleaner energy will increase throughout the next 10 to $15 \mathrm{yr}$. In all cases, CCHP becomes more favorable. Given these future prospects, it seems reasonable for governmental agencies to grant some economic incentives at present to a subgroup of farmers to implement CCHP within the next few years, and thereby better prepare the dairy industry to meet these potential future challenges.

\section{ACKNOWLEDGMENTS}

We acknowledge the New York State Energy Research and Development Authority (Albany) for providing financial support through the Environmental Monitoring, Evaluation, and Protection Program: Climate Change Adaptation Research (agreement no. 28264). We also thank Cornell University's Clinton-DeWitt and Ram Sagi Dairy Engineering Scholarship programs for partial financial support in completing this study.

\section{REFERENCES}

Alves, M. M., M. A. Pereira, D. Z. Sousa, A. J. Cavaleiro, M. Picavet, H. Smidt, and A. J. M. Stams. 2009. Waste lipids to energy: How to optimize methane production from long-chain fatty acids (LCFA). Microb. Biotechnol. 2:538-550.

Angelidaki, I., L. Ellegaard, and B. K. Ahring. 1999. A comprehensive model of anaerobic bioconversion of complex substrates to biogas. Biotechnol. Bioeng. 63:363-372.

Angenent, L. T., J. G. Usack, J. Xu, D. Hafenbradl, R. Posmanik, and J. W. Tester. 2018. Integrating electrochemical, biological, physical, and thermochemical process units to expand the applicability of anaerobic digestion. Bioresour. Technol. 247:1085-1094.
ASHRAE. 1995. Ammonia Refrigeration Systems in 2014 ASHRAE handbook. American Society of Heating, Refrigerating and AirConditioning Engineers Inc., Atlanta, GA.

Astals, S., D. J. Batstone, J. Mata-Alvarez, and P. D. Jensen. 2014. Identification of synergistic impacts during anaerobic co-digestion of organic wastes. Bioresour. Technol. 169:421-427.

Batstone, D. J., J. Keller, I. Angelidaki, S. V. Kalyuzhnyi, S. G. Pavlostathis, A. Rozzi, W. T. Sanders, H. Siegrist, and V. A. Vavilin. 2002a. Anaerobic Digestion Model no. 1 (ADM1). IWA, London, United Kingdom.

Batstone, D. J., J. Keller, I. Angelidaki, S. V. Kalyuzhnyi, S. G. Pavlostathis, A. Rozzi, W. T. Sanders, H. Siegrist, and V. A. Vavilin. 2002b. The IWA anaerobic digestion model no 1 (ADM1). Water Sci. Technol. 45:65-73.

Bishop, C. P., and C. R. Shumway. 2009. The economics of dairy anaerobic digestion with coproduct marketing. Rev. Agric. Econ. 31:394-410.

Collier, R. J., D. K. Beede, W. W. Thatcher, L. A. Israel, and C. J. Wilcox. 1982. Influences of environment and its modification on dairy animal health and production. J. Dairy Sci. 65:2213-2227.

Collier, R. J., G. E. Dahl, and M. J. Van Baale. 2006. Major advances associated with environmental effects on dairy cattle. J. Dairy Sci. 89:1244-1253

Cook, N. B., R. L. Mentink, T. B. Bennett, and K. Burgi. 2007. The effect of heat stress and lameness on time budgets of lactating dairy cows. J. Dairy Sci. 90:1674-1682.

Croxatto Vega, G. C., M. ten Hoeve, M. Birkved, S. G. Sommer, and S. Bruun. 2014. Choosing co-substrates to supplement biogas production from animal slurry - a life cycle assessment of the environmental consequences. Bioresour. Technol. 171:410-420.

Delcogliano, D. 2013. New York State Dairy Statistics. New York State Department of Agriculture and Markets: Division of Milk Control and Dairy Services, Albany, NY.

Dorgan, C. B. 1995. Application Guide for Absorption Cooling/Refrigeration Using Recovered Heat. American Society of Heating, Refrigerating and Air-Conditioning Engineers, Atlanta, GA.

Ebner, J. H., R. A. Labatut, M. J. Rankin, J. L. Pronto, C. A. Gooch, A. A. Williamson, and T. A. Trabold. 2015. Life-cycle greenhouse gas analysis of an anaerobic codigestion facility processing dairy manure and industrial food waste. Environ. Sci. Technol. 49:11199-11208.

EIA. 2014. New York Electricity Profile 2014. US Energy Information Administration, Washington, DC.

EIA. 2018. New York Electricity Profile 2018. US Energy Information Administration, Washington, DC.

Gebremedhin, K. G., B. Wu, and K. Perano. 2016. Modeling conductive cooling for thermally stressed dairy cows. J. Therm. Biol. 56:91-99.

Gebrezgabher, S. A., M. P. M. Meuwissen, B. A. M. Prins, and A. G. J. M. O. Lansink. 2010. Economic analysis of anaerobic digestion-A case of green power biogas plant in the Netherlands. NJAS Wagening. J. Life Sci. 57:109-115.

Gerber Van Doren, L., R. Posmanik, F. A. Bicalho, J. W. Tester, and D. L. Sills. 2017. Prospects for energy recovery during hydrothermal and biological processing of waste biomass. Bioresour. Technol. 225:67-74.

Internal Revenue Service. 2018. How to depreciate property. Publication 946. Cat. N. 13081F. US Department of the Treasury, Washington, DC

Jolliet, O., M. Margni, R. Charles, S. Humbert, J. Payet, G. Rebitzer, and R. Rosenbaum. 2003. IMPACT 2002+: A new life cycle impact assessment methodology. Int. J. Life Cycle Assess. 8:324-330.

Labatut, R. A. 2012. Anaerobic biodegradability of complex substrates: Performance and stability at mesophilic and thermophilic conditions. PhD Thesis. Department of Biological and Environmental Engineering, Cornell University, Ithaca, NY.

Liu, D. Y., S. J. He, S. Q. Liu, Y. G. Tang, E. H. Jin, H. L. Chen, S. H. Li, and L. T. Zhong. 2014. Daidzein enhances immune function in late lactation cows under heat stress. Anim. Sci. J. 85:85-89. 
Lübken, M., M. Wichern, M. Schlattmann, A. Gronauer, and H. Horn. 2007. Modelling the energy balance of an anaerobic digester fed with cattle manure and renewable energy crops. Water Res. 41:4085-4096.

Norman, H. D., R. H. Miller, J. R. Wright, J. L. Hutchison, and K. M. Olson. 2012. Factors associated with frequency of abortions recorded through Dairy Herd Improvement test plans. J. Dairy Sci. 95:4074-4084.

Perano, K. M., J. G. Usack, L. T. Angenent, and K. G. Gebremedhin. 2015. Production and physiological responses of heat-stressed lactating dairy cattle to conductive cooling. J. Dairy Sci. 98:52525261.

Poeschl, M., S. Ward, and P. Owende. 2010. Evaluation of energy efficiency of various biogas production and utilization pathways. Appl. Energy 87:3305-3321.

Posmanik, R., C. M. Martinez, B. Cantero-Tubilla, D. A. Cantero, D. L. Sills, M. J. Cocero, and J. W. Tester. 2018. Acid and alkali catalyzed hydrothermal liquefaction of dairy manure digestate and food waste. ACS Sustainable Chem. Eng. 6:2724-2732. https://doi .org/10.1021/acssuschemeng.7b04359.

Rotz, C. A. 2012. The Integrated Farm System Model Software for Evaluating the Performance, Environmental Impact and Economics of Farming Systems. United States Department of Agriculture, Washington, DC.

Sanscartier, D., H. L. MacLean, and B. Saville. 2012. Electricity production from anaerobic digestion of household organic waste in Ontario: techno-economic and GHG emission analyses. Environ. Sci. Technol. 46:1233-1242.

Song, Y. C., S. J. Kwon, and J. H. Woo. 2004. Mesophilic and thermophilic temperature co-phase anaerobic digestion compared with single-stage mesophilic- and thermophilic digestion of sewage sludge. Water Res. 38:1653-1662.

St-Pierre, N. R., B. Cobanov, and G. Schnitkey. 2003. Economic losses from heat stress by US livestock industries. J. Dairy Sci. 86:52-77.

Stull, C. L., L. L. M. Messam, C. A. Collar, N. G. Peterson, A. R. Castillo, B. A. Reed, K. L. Andersen, and W. R. VerBoort. 2008. Precipitation and temperature effects on mortality and lactation parameters of dairy cattle in California. J. Dairy Sci. 91:4579-4591.

Thomassen, M. A., K. J. v. Calker, M. C. J. Smits, G. Iepema, and I. J. M. d. Boer. 2008. Life cycle assessment of conventional and organic milk production in the Netherlands. Agric. Syst. 96:95-107.

Upton, J., J. Humphreys, P. W. G. G. Koerkamp, P. French, P. Dillon, and I. J. M. De Boer. 2013. Energy demand on dairy farms in Ireland. J. Dairy Sci. 96:6489-6498.

Usack, J. G., and L. T. Angenent. 2015. Comparing the inhibitory thresholds of dairy manure co-digesters after prolonged acclimation periods: Part 1-Performance and operating limits. Water Res. 87:446-457.

Usack, J. G., L. Gerber Van Doren, R. Posmanik, R. A. Labatut, J. W. Tester, and L. T. Angenent. 2018. An evaluation of anaerobic co-digestion implementation on New York State dairy farms using an environmental and economic life-cycle framework. Appl. Energy 211:28-40.

Zaher, U., R. Li, U. Jeppsson, J. P. Steyer, and S. Chen. 2009. GISCOD: General integrated solid waste co-digestion model. Water Res. 43:2717-2727.

Zhou, H., D. Löffler, and M. Kranert. 2011. Model-based predictions of anaerobic digestion of agricultural substrates for biogas production. Bioresour. Technol. 102:10819-10828. 
APPENDIX
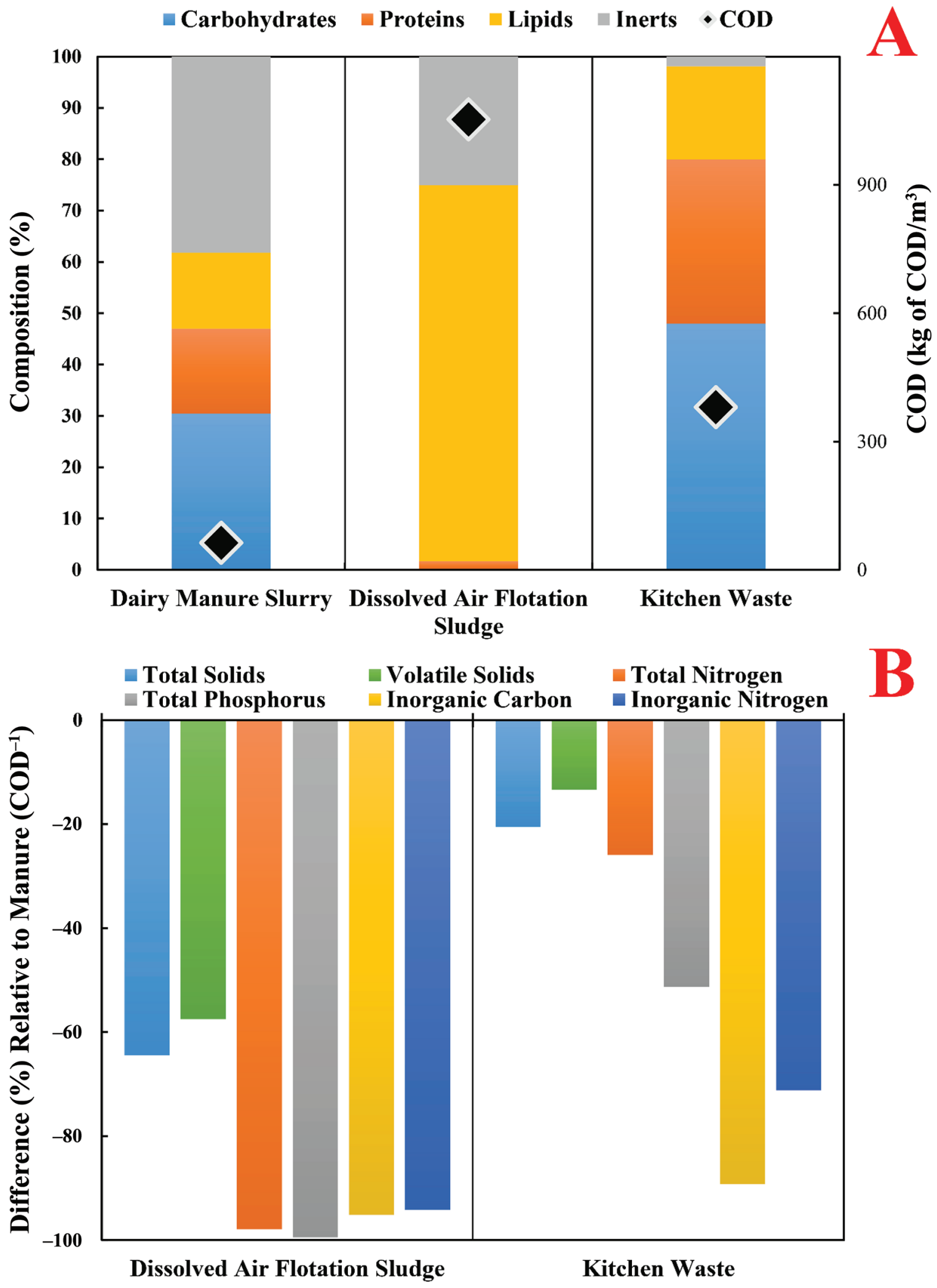

Figure A1. (A) The organic composition of the anaerobic digestion feedstock (primary axis) based on the chemical oxygen demand (COD; secondary axis). (B) Physical and chemical characteristics of the co-substrates normalized to dairy manure slurry and COD. 


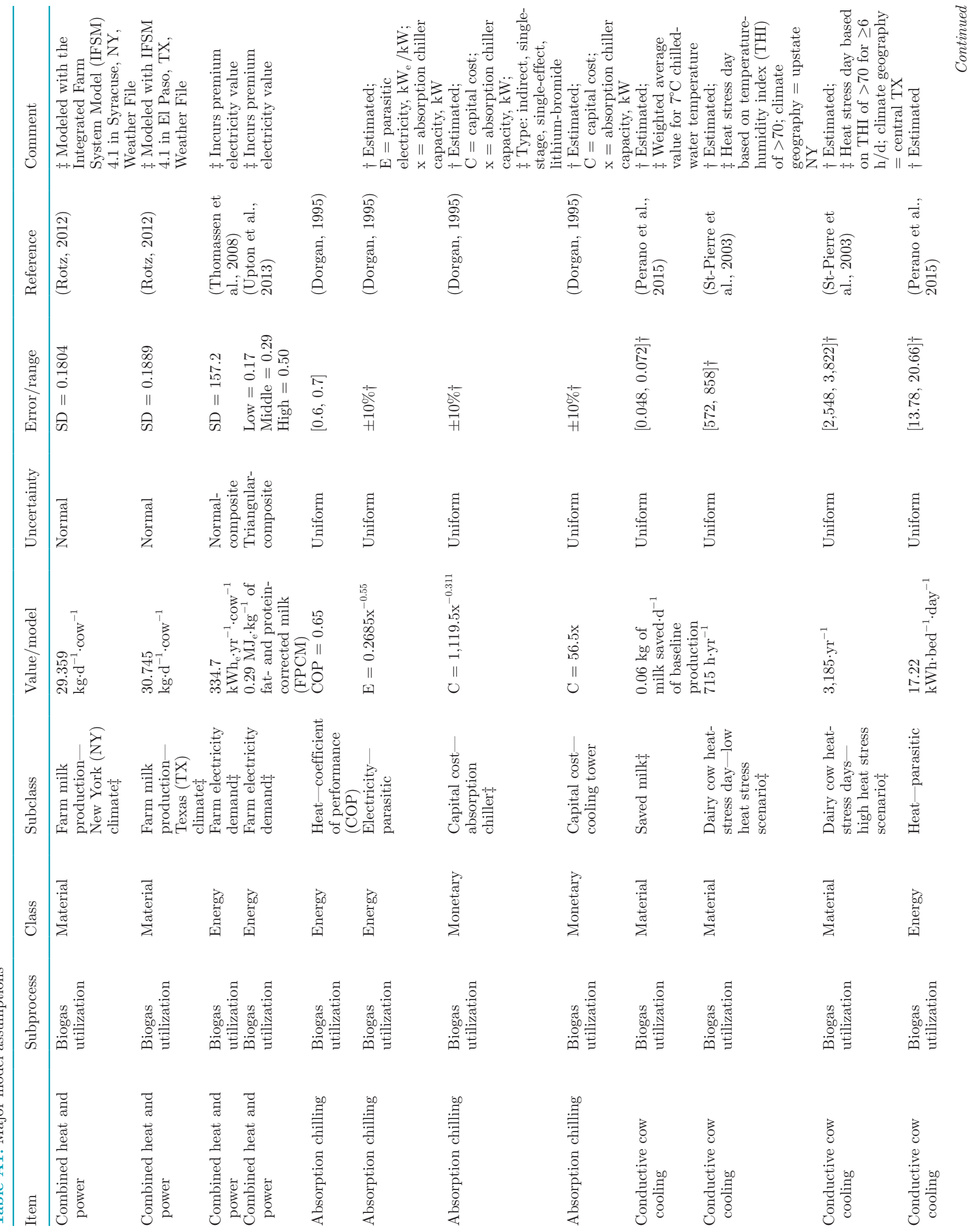


COMBINED COOLING, HEAT, AND POWER ON DAIRY FARMS
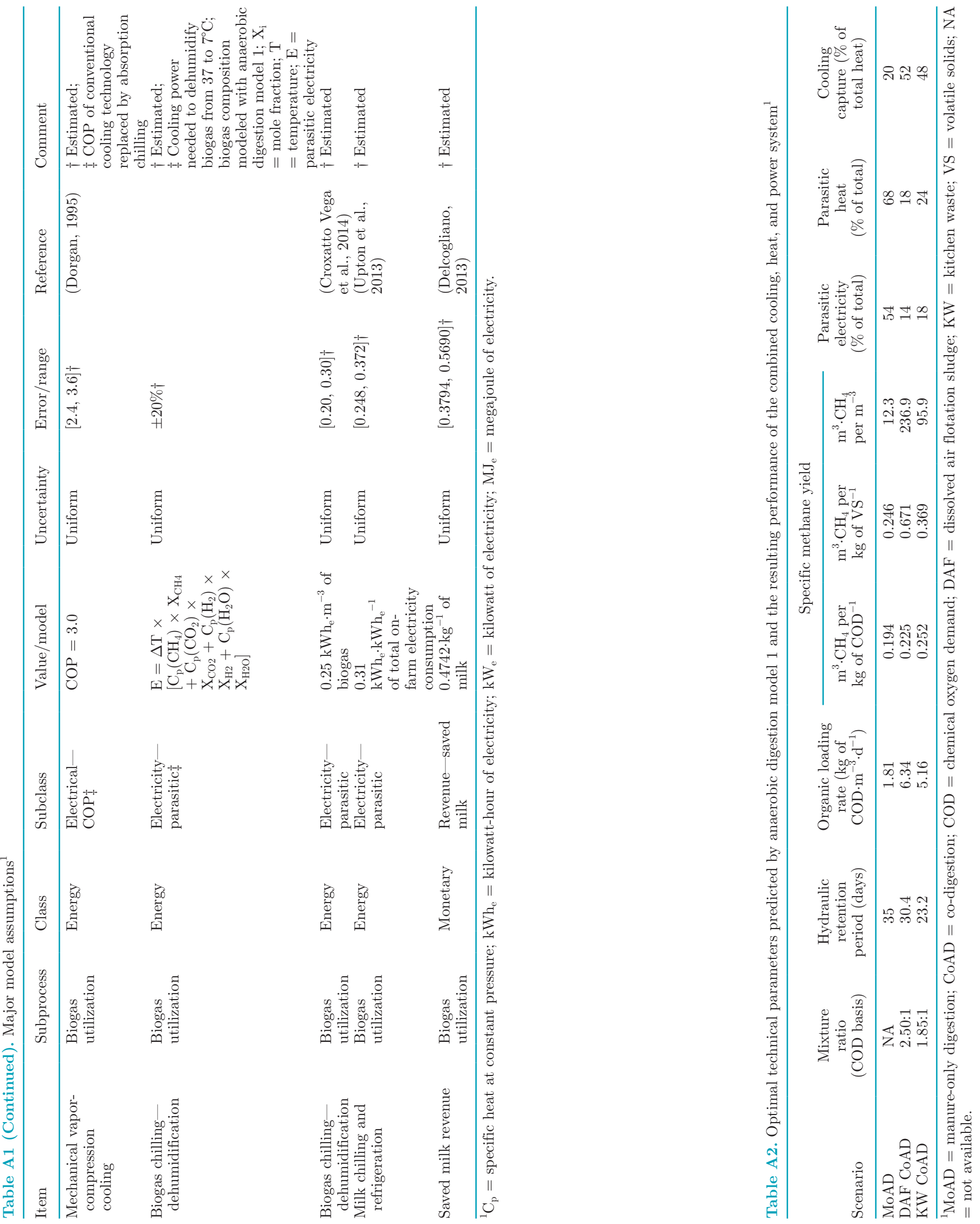